\title{
Surgical anatomy of caudate bile ducts: Silicon-injected cadaveric-livers dissected under magnification
}

\author{
Antonio Cavalcanti de A. Martins ${ }^{1,2}$ and Carolina Martins $\mathbf{s}^{3,4}$ \\ ${ }^{1}$ Department of Surgery, Instituto de Medicina Integral Prof. Fernando Figueira (IMIP), \\ ${ }^{2}$ Anatomy Laboratory, Medical School of Pernambuco (FPS), \\ ${ }^{3}$ College of Medicine, Federal University of Pernambuco, \\ ${ }^{4}$ Department of Surgery, Pelópidas Silveira Hospital, Recife, PE, Brazil
}

\begin{abstract}
Backgrounds/Aims: Caudate bile ducts are routinely presented using negative images as X-ray-cholangiograms. Such information does not provide for instant surgical orientation of the relationships between caudate ducts and the liver itself-a paramount skill for successfully performing hilar cholangiocarcinoma resection and living donor/split transplantation. This study presents a 4-step procedure to prepare, dissect and present, high-quality, 2D/3D anatomical images of biliary caudate ducts in a surgically meaningful way. Methods: Fresh cadavers had arteries and veins injected with colored-silicone and ducts bile-stained to facilitate recognition. Dissections were performed under magnification with microsurgical instruments. Stepwise 2D and 3D images were acquired. Results: Dissection of silicone-injected specimens under magnification allows identification of caudate structures, its portions and processes while preserving tridimensional arrangement of caudate vessels, biliary ducts and collectors. Such dissections can help enhance cholangiogram interpretation and favor its direct correlation to intraoperative findings. Conclusions: A procedure including: a) preparation of high-quality cadaveric livers, b) with silicone-injected vessels, c) dissected under surgical microscope and d) documented using $2 \& 3 \mathrm{D}$ images aimed at enhancing the clinical understanding of the anatomy of caudate ducts is presented. It has potential to enhance morphological and clinical understanding of caudate ducts, being useful to anatomists and surgeons alike. (Ann Hepatobiliary Pancreat Surg 2020;24:415-420)
\end{abstract}

Key Words: Liver; Anatomy; Bile ducts

\section{INTRODUCTION}

The biliary ducts of the caudate lobe must be dealt with during two major hepatobiliary surgical procedures: a) hilar cholangiocarcinoma resection ${ }^{1,2}$ and b) living donor/ split liver transplantation. ${ }^{3,4}$ Surgical maneuvers and complication avoidance in both procedures involve detailed anatomical knowledge of this area.,

Caudate bile duct anatomy has been extensively described using X-ray cholangiograms, ${ }^{7}$ CT cholangiogram, ${ }^{8-10}$ magnetic resonance cholangiopancreatography $(\mathrm{MRCP})^{11}$ and liver corrosion casts. ${ }^{6,7,12}$ Because these are negative-image data, these methods fail to provide surgeons with information on the relationships between ducts and surrounding structures-as portal vein, arteries and the caudate lobe itself-and in demonstrating the microsurgical anatomy of the biliary ducts, including the second and third order branches to portions of caudate as paracaval, caudate process and Spiegel lobe.

This study presents a 4-step procedure to prepare, dissect and present, high-quality, 2D/3D anatomical images of biliary caudate ducts in a surgically meaningful way.

\section{MATERIALS AND METHODS}

\section{Selection \& preparation}

Anatomical specimens were obtained from the Anatomical Board of the State of Florida. Injection and dissections were undertaken at the George Schrader Colter International Anatomical Lab (Gainesville, US). This stud-

Received: May 5, 2020; Revised: May 31, 2020; Accepted: June 7, 2020

Corresponding author: Antonio Cavalcanti de A. Martins

Department of Surgery, Instituto de Medicina Integral Prof. Fernando Figueira (IMIP), Pedro Pires Ferreira St, 325/1601, Graças, Recife, PE 52050-480, Brazil

Tel: +55-81-999738223, Fax: +55-81-21224122, E-mail: antoniocavalcantideamartins@gmail.com

Copyright (C) 2020 by The Korean Association of Hepato-Biliary-Pancreatic Surgery

This is an Open Access article distributed under the terms of the Creative Commons Attribution Non-Commercial License (http://creativecommons.org/ licenses/by-nc/4.0) which permits unrestricted non-commercial use, distribution, and reproduction in any medium, provided the original work is properly cited. Annals of Hepato-Biliary-Pancreatic Surgery • pISSN: 2508-5778 • elSSN: 2508-5859 

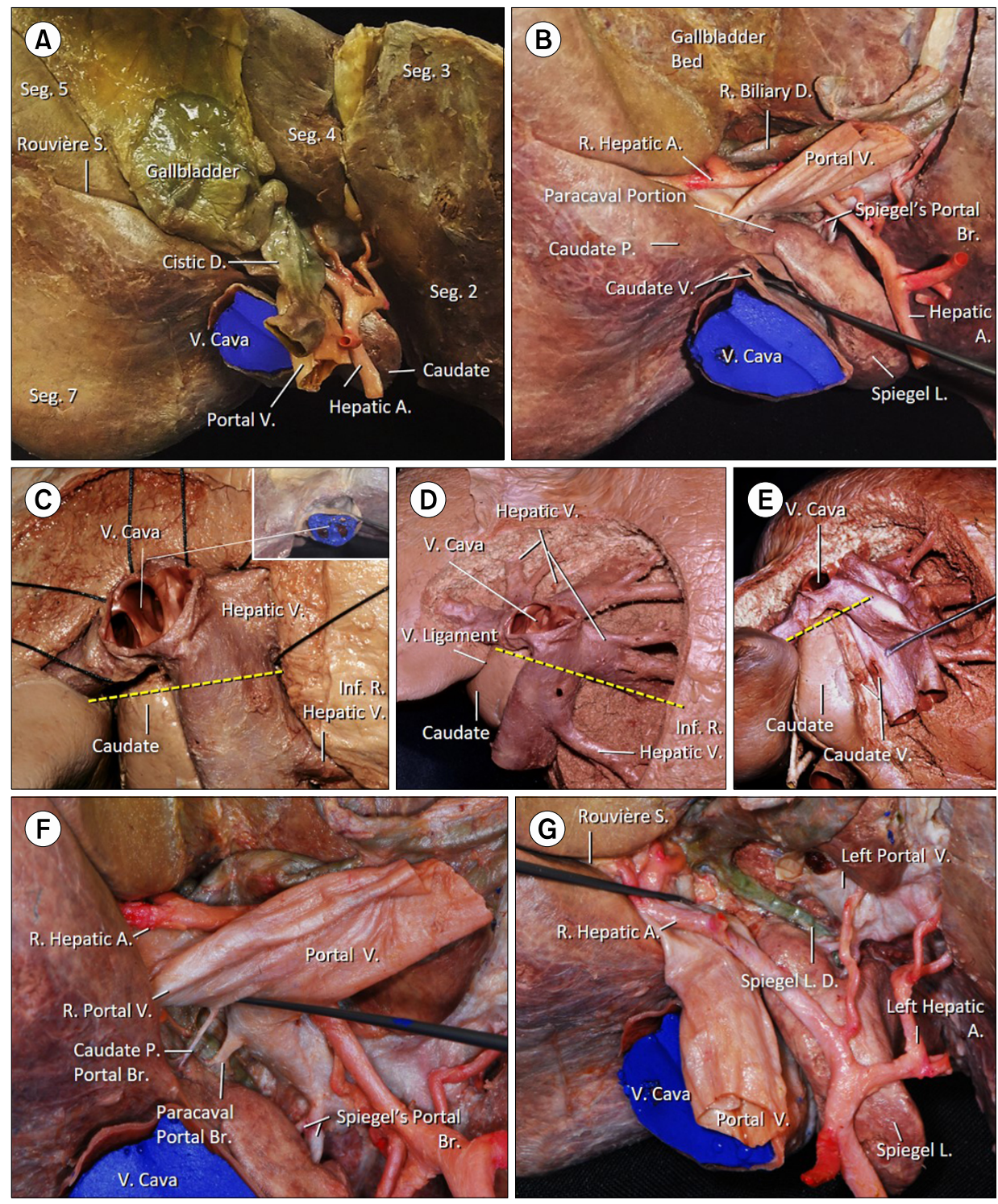

Fig. 1. (A) Visceral surface of an injected liver. The vena cava is highlighted by the blue silicone and provides instant orientation around the porta hepatis. The gallbladder has a redundant cystic duct. Although not injected, the bile staining allows their clear differentiation from the red silicone-injected arterial branches. (B) Enlarged view of the caudate lobe and its parts after resection of the gallbladder. The common biliary duct and the portal vein have been displaced superiorly. According to Kumon, ${ }^{6}$ the caudate is divided into Spiegel lobe, paracaval portion and the caudate process. Much is debated about the boundaries of these three portions. The magnification allows identification of minute caudate structures. A microsurgical dissector depresses vena cava's anterior wall, displaying the veins draining the caudate process. At this level there are two notches, close to the transition between the caudate process and the paracaval portion. These notches should not be confused with Kogure et al. ${ }^{17}$ external caudate notch. Although the external caudate notch as described by these authors is not present in this specimen, a slight indentation can be seen along the anterior caudate surface in relation to Spiegel lobe's portal branches. (C) Posterior view of the diaphragmatic surface of the liver. The hepatic veins have been isolated using black ligatures. The superior pole of caudate corresponds to the venous confluence into suprahepatic vena cava (yellow dotted line). Insert: corresponding view of an injected specimen. (D) Liver parenchyma has been resected to expose venous tributaries of the major hepatic veins. This specimen presents an inferior right hepatic vein. (E) A microsurgical dissector has been used to displace the retro hepatic vena cava. A caudate vein can be seen entering its middle third. (F) The portal vein has been elevated to display caudate's portal branches. The dissector is located at the level of portal bifurcation. Located to the right are a caudate process portal branch and the right portal vein. Paracaval and Spiegel's lobe portal branches can be seen joining the left portal vein. A biliary duct can be devised through the spaces between these portal branches. (G) The portal vein has been partially resected to expose the caudate ducts. The duct partially visualized in (F) is in fact a Spiegel's biliary duct passing along the anterior surface of the caudate to join the major biliary collectors. 
ied has been registered at the Institutional Review Board PAAP-HPS 202069371604.

Fixation of fresh whole cadavers was accomplished after thorough saline cleanse of the vascular tree and arterial injection of formalin $10 \%$. Specimens were kept refrigerated $\left(-4^{\circ} \mathrm{C}\right)$ until whole-body arterial silicon injection and/or liver harvesting.

Using fresh cadavers treated so early, ducts were bilestained and were easily recognizable during dissection.

\section{Silicone injection}

In specimens that underwent silicone injection, arteries and veins were perfused with red and blue colored silicone using Rhoton's Lab technique, commonly used in microsurgical anatomy labs around the world and well stablished in Neurosurgery and ENT studies in surgical anatomy. $^{13,14}$

\section{Dissection}

Six livers were used in this study. After inspected in
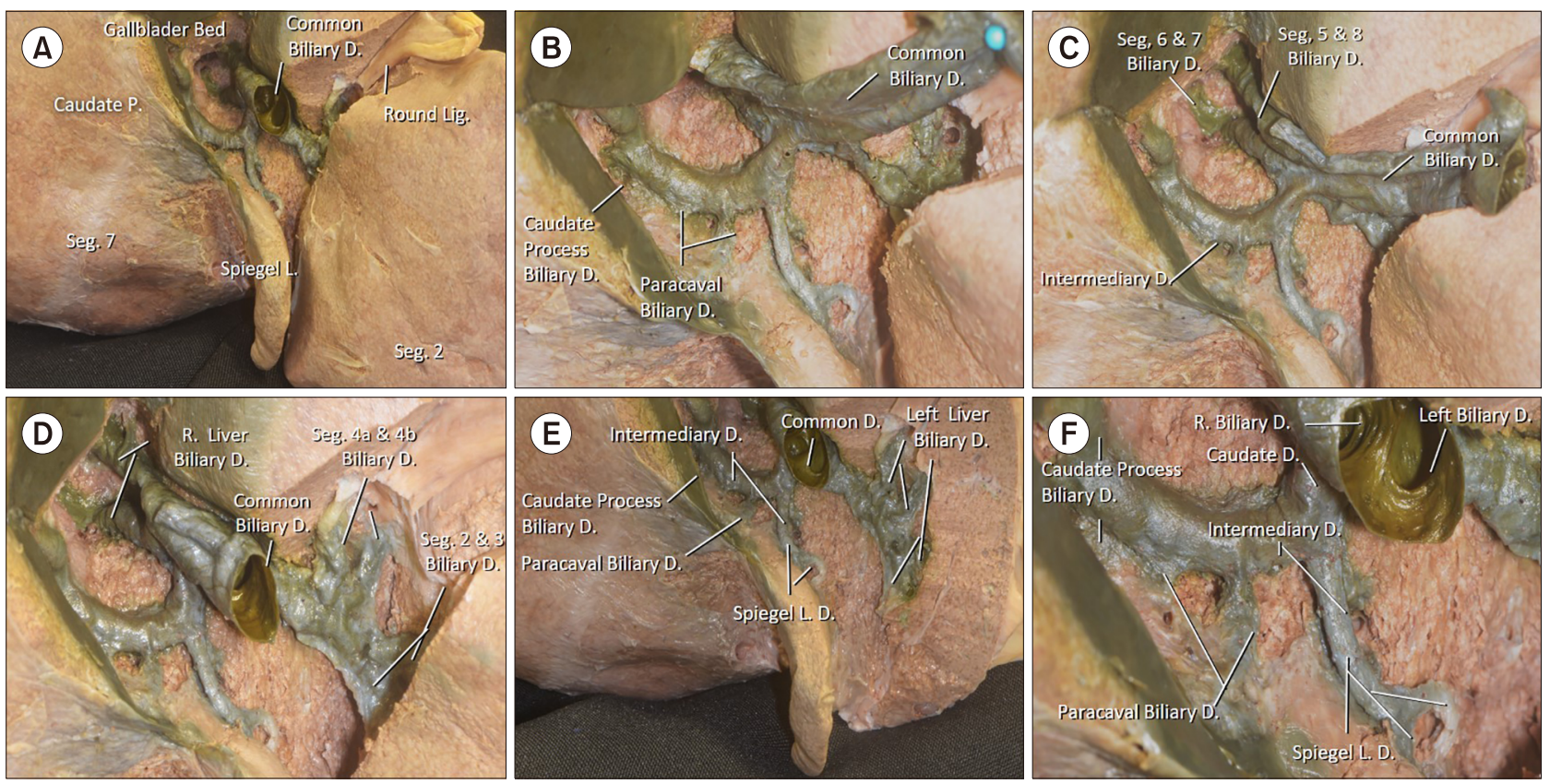

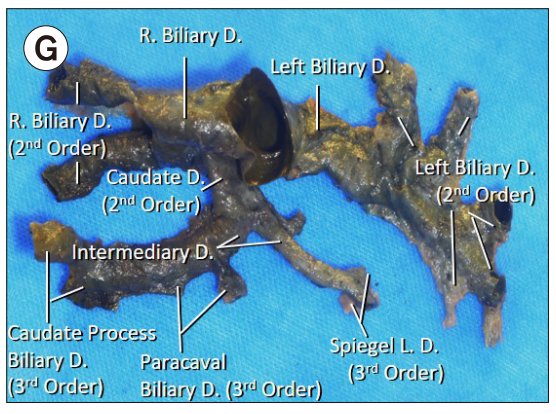

Fig. 2. Microsurgical dissection of the caudate biliary ducts after removal of vascular structures along the porta hepatis. This specimen (L1) has been chosen as its anatomical arrangement can be expected in less than $5 \%$ of livers studied by cholangiography, according to Healey and Schroy ${ }^{7}$ and its anatomical images have seldom been presented. (A) Overview of porta hepatis after removal of arterial and venous branches. (B) Enlarged view of (A). Several biliary ducts drain the caudate and form a common biliary caudate collector that joins the major ducts close to its bifurcation. (C) Biliary ducts to the right liver have been exposed. In this specimen, biliary ducts draining the caudate process and paracaval portion collect into an intermediary duct. (D) Parenchymal resection has been undertaken to expose the biliary ducts to the left liver. (E) Caudate process and paracaval biliary ducts join into an intermediary duct. An intermediary duct also collects a set of short ducts from Spiegel lobe. These intermediary ducts join to form a single caudate biliary duct. (F) Although the caudate duct seems to join the major ducts at the bifurcation, view through the common duct lumen shows that this junction involves in fact the right duct. This specimen may explain differences between cholangiography descriptions and surgical findings. (G) The ductal tree has been resected to display its draining pattern. This last step on each dissection has served as model for the summarized data on Table 1. 
situ, each liver was resected by sectioning supra and infrahepatic vena cava and the distal liver pedicle.

Dissections were performed using $3 \times$ to $14 \times$ magnification of a surgical microscope (S21 Surgical Microscope; Carl Zeiss AG, Oberkochen, Germany) and standard microsurgical instruments.

The hilar fissure was fully dissected and exposed under magnification. All the connective tissue originated from Glisson's capsule was cleaned from the hilar fissure (hilar plate total resection) to highlight the complete extra-hepatic relations of the caudate ducts and its bifurcations before entering the liver tissue.

The last dissection step was accomplished by total removal of vascular (portal and arterial) branches around Segment 1 to expose the caudate ducts and its relations to the lobe itself.

\section{D \& 3D documentation}

Stepwise 2D and 3D images were acquired using Nikon cameras (D80, D5100 and P100, Nikon Corp., Tokyo, Japan) and Nikon lenses (Nikon microlenses 2.0, $105 \mathrm{~mm}$, Nikon Corp., Japan). 3D images were also acquired using Fuji cameras (Finepix Real 3D W1 and W3, Fuji Film Corp., Japan). All pictures were taken using a slidebar attached to a Manfrotto tripod (Manfrotto B55 tripod, Manfrotto, Italy). A ring flash was also used (Sigma Corp., Japan). ${ }^{15,16}$

\section{RESULTS}

The anatomical relationships exposed using this 4-step procedure are presented on Fig. 1 (silicone-injected specimens) and Fig. 2 (cleaned hilar fissure: ducts-only specimen) and summarized on Table 1.

The stepwise dissection under magnification allows identification of minute caudate structures and allows differentiation of caudate portions and processes. The tridimensional arrangement of caudate draining veins can be appreciated, and the biliary ducts and collectors followed. Such dissections can help enhance cholangiogram interpretation and favor its direct correlation to intraoperative findings.

To further exemplify the application of this 4-step procedure in highlighting the caudate ducts anatomy, images of a seldom-presented pattern of caudate biliary ducts
Table 1. Summarized data on dissected specimens

\begin{tabular}{|c|c|c|c|}
\hline Specimen & Artery & Portal & Duct \\
\hline Liver $1 *$ & $\begin{array}{l}2 \text { branches: } \\
1 \text { left hepatic artery } \\
1 \text { Seg } 6 / 7 \text { artery }\end{array}$ & $\begin{array}{l}3 \text { branches: } \\
1 \text { right portal } \\
2 \text { left portal }\end{array}$ & \\
\hline Liver 2 & $\begin{array}{l}3 \text { branches: } \\
2 \text { left hepatic artery } \\
1 \text { Seg } 6 / 7 \text { artery }\end{array}$ & $\begin{array}{l}4 \text { branches: } \\
1 \text { right portal } \\
2 \text { left portal } \\
1 \text { main portal }\end{array}$ & \\
\hline Liver 3 & $\begin{array}{l}2 \text { branches: } \\
2 \text { left hepatic artery }\end{array}$ & $\begin{array}{l}4 \text { branches: } \\
1 \text { right portal } \\
1 \text { left portal } \\
2 \text { main portal }\end{array}$ & \\
\hline Liver 4 & $\begin{array}{l}2 \text { branches: } \\
1 \text { left hepatic artery } \\
1 \text { accessory } \\
\text { right artery }\end{array}$ & $\begin{array}{l}2 \text { branches: } \\
1 \text { right portal } \\
1 \text { main portal }\end{array}$ & \\
\hline Liver 5 & $\begin{array}{l}3 \text { branches: } \\
1 \text { left hepatic artery } \\
2 \text { right hepatic artery }\end{array}$ & $\begin{array}{l}3 \text { branches: } \\
1 \text { right portal } \\
1 \text { left portal } \\
1 \text { main portal }\end{array}$ & \\
\hline Liver 6 & $\begin{array}{l}2 \text { branches: } \\
1 \text { right hepatic artery } \\
1 \text { accessory } \\
\text { left artery }\end{array}$ & $\begin{array}{l}3 \text { branches: } \\
1 \text { right portal } \\
1 \text { main portal }\end{array}$ & \\
\hline
\end{tabular}

*Liver depicted on Figs. 1 and 2

have been chosen (Fig. 2). This specimen (Liver 1) has a common caudate duct, that collect all portions of Segment 1, entering the confluence of the right and left hepatic ducts. This pattern was observed by Healey and Schroy ${ }^{7}$ in $5 \%$ of livers, ${ }^{17}$ studied using cholangiography.

\section{DISCUSSION}

Anatomical understanding of the liver has changed in the last 2,000 years. Galen described 5-lobed livers in apes $^{18}$ and even Vesalius ${ }^{19}$ perpetuated this misunderstanding in his Fabrica. Till renaissance, the internal liver anatomy had seldom been described.

In 1654, Francis Glisson described the inner anatomy of the liver (and its capsule/envelop) using "cooking" and "ants-digestion" methods, earlier described by Spiegel. Glisson named those methods "liver-defleshing", as the final result would be a cast of intrahepatic vessels. ${ }^{20}$

The enlightenment and the modern era brought the availability of organs to be studied (and injected), culminating with the studies of Cantlie, MacIndoe \& Counseller, Hjortsjo, Goldsmith \& Woodburne and Couinaud. ${ }^{21,22}$ Couinaud and his collection of corrosion casts revolutionized 
the anatomical knowledge of the liver. ${ }^{22}$

For the last 50 years, attention has been driven towards the caudate. Its anatomy has been studied using several methods. ${ }^{7,9,11,12}$

Considering the caudate lobe complexity, divisions and micro-anatomical architecture, its published anatomical data has been mainly limited to "negative images", including corrosion casts or X-ray cholangiograms. The missing relationships between caudate ducts and the liver itself are shortcomings of such methodologies. To further increase the difficulties in obtaining a realistic, surgically oriented representations of the caudate ducts, are articles presenting macroscopically dissected (de-fleshed), black-and-white figures of caudate lobes without differentiation between arteries, veins, portal branches and ducts. ${ }^{15,23,24}$

Based on techniques described and routinely used in other areas of anatomical knowledge, this study comprises a 4-step procedure that includes: a) preparation of highquality cadaveric livers, b) with silicone-injected arteries and veins an stained biliary ducts to facilitate recognition, c) dissected under surgical microscope and d) documented using $2 \& 3 \mathrm{D}$ images aimed at enhancing the clinical understanding of the anatomy of caudate. Its application has the potential to enhance clinical and morphological of the caudate ducts, being of interest to anatomists and surgeons alike.

\section{CONFLICT OF INTEREST}

The authors declare no conflict of interest for this article.

\section{ORCID}

\author{
Antonio Cavalcanti de A. Martins: \\ https://orcid.org/0000-0002-1249-8622 \\ Carolina Martins: https://orcid.org/0000-0002-0197-3520
}

\section{AUTHOR CONTRIBUTIONS}

Conceptualization: ACAM. Data curation: ACAM, CM. Formal analysis: ACAM, CM. Methodology: ACAM, CM. Project administration: ACAM, CM. Visualization: CM. Writing - original draft: ACAM, CM. Writing - review \& editing: AM, CM.

\section{REFERENCES}

1. Nagino M, Kamiya J, Arai T, Nishio H, Ebata T, Nimura Y. "Anatomic" right hepatic trisectionectomy (extended right hepatectomy) with caudate lobectomy for hilar cholangiocarcinoma. Ann Surg 2006;243:28-32.

2. Sugiura T, Nagino M, Kamiya J, Nishio H, Ebata T, Yokoyama $\mathrm{Y}$, et al. Infraportal bile duct of the caudate lobe: a troublesome anatomic variation in right-sided hepatectomy for perihilar cholangiocarcinoma. Ann Surg 2007;246:794-798.

3. Hwang S, Lee SG, Ha TY, Ahn CS, Park KM, Kim KH, et al. Simplified standardized technique for living donor liver transplantation using left liver graft plus caudate lobe. Liver Transpl 2004;10:1398-1405.

4. Kubota K, Takayama T, Sano K, Hasegawa K, Aoki T, Sugawara Y, et al. Small bile duct reconstruction of the caudate lobe in living-related liver transplantation. Ann Surg 2002;235: 174-177.

5. Abdalla EK, Vauthey JN, Couinaud C. The caudate lobe of the liver: implications of embryology and anatomy for surgery. Surg Oncol Clin N Am 2002;11:835-848.

6. Kumon M. Anatomical study of the caudate lobe with special reference to portal venous and biliary branches using corrosion liver casts and clinical application. Liver Cancer 2017;6:161-170.

7. Healey JE Jr, Schroy PC. Anatomy of the biliary ducts within the human liver; analysis of the prevailing pattern of branchings and the major variations of the biliary ducts. AMA Arch Surg 1953;66:599-616.

8. Makki K, Chorasiya V, Srivastava A, Singhal A, Khan AA, Vij V. Analysis of caudate lobe biliary anatomy and its implications in living donor liver transplantation - a single centre prospective study. Transpl Int 2018;31:1041-1049.

9. Edo H, Sekiguchi R, Edo N, Kajiyama A, Nagamoto M, Gomi T. Evaluation of biliary anatomy in the caudate lobe using drip infusion cholangiography-computed tomography. Abdom Radiol (NY) 2019;44:886-893.

10. Ryu M, Cho A. New liver anatomy- portal segmentation and the drainage vein. Tokyo: Springer Japan, 2009.

11. Hyodo T, Kumano S, Kushihata F, Okada M, Hirata M, Tsuda T, et al. CT and MR cholangiography: advantages and pitfalls in perioperative evaluation of biliary tree. $\mathrm{Br} \mathrm{J}$ Radiol 2012;85:887-896.

12. Gadzijev EM, Ravnik D. Atlas of applied internal liver anatomy. New York: Springer, 1996.

13. Sanan A, Abdel Aziz KM, Janjua RM, van Loveren HR, Keller JT. Colored silicone injection for use in neurosurgical dissections: anatomic technical note. Neurosurgery 1999;45:12671271; discussion 1271-1274.

14. Shimizu S, Tanaka R, Rhoton AL Jr, Fukushima Y, Osawa S, Kawashima M, et al. Anatomic dissection and classic three-dimensional documentation: a unit of education for neurosurgical anatomy revisited. Neurosurgery 2006;58:E1000; discussion E1000.

15. Martins C, Ribas EC, Rhoton AL Jr, Ribas GC. Three-dimensional digital projection in neurosurgical education: technical note. J Neurosurg 2015;123:1077-1080.

16. Martins C, Alencastro LF, Campero A, Rhoton A Jr. Three-dimensional endoscopic photography of anatomic specimens. World Neurosurg 2018;120:e730-e736.

17. Kogure K, Kuwano H, Fujimaki N, Makuuchi M. Relation among portal segmentation, proper hepatic vein, and external notch of the caudate lobe in the human liver. Ann Surg 2000;231:223228.

18. Rajkumari A. Galen and his contribution to anatomy: a review. 
J Evol Med Dent Sci 2015;4:4509-4516.

19. Vesalius A. The fabric of the human body; an annotated translation of the 1543 and 1555 edition of "De humani corporis fabrica libri septem". by D.H. Garrison and M.H. Hast. Basel: Basel Freiburg Karger, 2016.

20. Walker RM. Francis Glisson and his capsule. Ann R Coll Surg Engl 1966;38:71-91.

21. Fortner JG, Blumgart LH. A historic perspective of liver surgery for tumors at the end of the millennium. J Am Coll Surg 2001;
193:210-222.

22. Sutherland F, Harris J. Claude Couinaud: a passion for the liver. Arch Surg 2002;137:1305-1310.

23. Lee UY, Murakami G, Han SH. Arterial supply and biliary drainage of the dorsal liver: a dissection study using controlled specimens. Anat Sci Int 2004;79:158-166.

24. Murakami G, Hata F. Human liver caudate lobe and liver segment. Anat Sci Int 2002;77:211-224. 